\title{
Crianças e adolescentes na condição de pacientes médicos: desafios da ponderação entre autonomia e vulnerabilidade
}

\author{
Children and adolescents as medical patients: \\ challenges of balancing autonomy and vulnerability
}

\author{
Carlos Nelson Konder \\ Ana Carolina Brochado Teixeira*
}

\section{Resumo}

Em face da centralidade da pessoa humana no ordenamento jurídico brasileiro, rompe como novo sujeito de direito o paciente menor de idade. Antes, o paciente era objeto da relação com seu médico, pois este era o gestor e o responsável pela definição dos rumos do tratamento. Da mesma forma, o menor era tido como sujeito passivo da relação com seus pais, nada definindo no seu processo educacional. Dessa situação de invisibilidade, a tutela do paciente menor de idade tornou-se imperativa, na medida em que o paciente transformou-se no protagonista decisório do seu tratamento e o menor, participante ativo da relação com seus pais. O paciente menor de idade deve ser protegido em suas fragilidades - posto que vulnerável -, mas sem ignorar as manifestações autônomas dos seus desejos.

Palavras-chave: Relação médico paciente. Criança e adolescente. Autoridade parental. Discernimento. Autonomia.

\section{Abstract}

Given the centrality of the human person in the brazilian legal system, minor patients emerge as a new subject of law. Before, the patient was the object of

Doutor em Direito Civil pela UERJ. Especialista (2009) em Direito Civil pela Università di Camerino (Itália). Professor adjunto do Departamento de Direito Civil da Faculdade de Direito da Universidade do Estado do Rio de Janeiro (UERJ). Rio de Janeiro - RJ - Brasil. Email: c.konder@ gmail.com

** Doutorado na UERJ (2009). Atualmente é professora do Centro Universitário UNA e advogada. Belo Horizonte - MG - Brasil. Email: anacarolina.bt@uol.com.br 
the relationship with his doctor, who was responsible for defining the course of treatment. Similarly, minor patient was regarded passively in the relationship with their parents, with no interference in his educational process. From this situation of invisibility, the protection of minor patient became imperative, since the patient became protagonist of his treatments decisions and the minor became active participant in the relationship with his parents. The minor patient should be protected in his weaknesses - since vulnerable - but without ignoring the autonomous manifestations of his desires.

Keywords: Doctor patient relationship. Children and adolescents. Parental authority. Discernment. Autonomy.

\section{Introdução}

O desenvolvimento contemporâneo do Direito Civil levou-o a descer do pedestal das construções teóricas puras e pretensamente válidas em qualquer época e local para buscar oferecer soluções a problemas reais e concretos, contingentes a determinados contextos. Em lugar da elaboração de estruturas neutras, categorias vêm sendo formuladas e reinterpretadas sob uma perspectiva funcional: com o objetivo de satisfazer valores e interesses concretos eleitos politicamente pelo texto constitucional.

Nessa seara, exsurgem a criança e o adolescente, que receberam proteção prioritária pelo constituinte, a qual, veiculada especialmente pela Lei $n^{\circ} 8.069 / 90$, reconheceu a possibilidade de o menor de idade assumir uma postura ativa nos processos decisórios relativos à sua pessoa, na medida, contudo, de sua maturidade e discernimento.

Na mesma linha, também a relação médico-paciente vem sendo objeto de releitura, pois a figura do médico paternalista, que sabe o caminho certo e toma as decisões sozinho, vem sendo substituída pelo protagonismo do paciente, cuja autonomia existencial é respeitada, pois é capaz de formular a própria concepção de saúde.

O objeto deste artigo são os desafios a serem enfrentados para proteger o paciente menor de idade na relação simultaneamente 
desenvolvida com seus pais e com a equipe médica, sopesando sua autonomia e vulnerabilidade.

\section{Da invisibilidade à vulnerabilidade: a criança paciente como novo sujeito de direito}

A categoria da "vulnerabilidade", em sua expressão mais literal, é oriunda dos debates sobre saúde pública, sendo referida a sujeitos mais suscetíveis de serem feridos, mas, com certo alargamento no seu significado, ganhou enorme importância e prestígio no Direito (BARBOZA, 2009, p. 114). Ela aporta uma sensibilidade às situações concretas que o pensamento jurídico clássico não se permitia.

De fato, uma das marcas do pensamento jurídico dos séculos XVIII e XIX é a abstração, a construção de categorias jurídicas puras e imutáveis, aptas a serem empregadas em qualquer lugar, época e situação (BOBBIO, 1977, p. 65). Esse tipo de abordagem atendia ao anseio de garantir autonomia científica ao Direito, então ameaçado de absorção pela Sociologia, e também à busca de igualdade formal, pretensão da burguesia ascendente em oposição ao sistema estamental e aos privilégios aristocráticos (ASCENSÃO, 2005, p. 346).

Nessa forma de pensar, só existia um sujeito para o Direito: o sujeito de direito. Uma categoria aberta e asséptica o suficiente para tratar todos, em qualquer situação, da mesma maneira, assegurando o atendimento aos interesses em jogo (FACHIN, 2000, p. 13-14). A tutela desse sujeito, por sua vez, era assegurada essencialmente por meio de garantias à sua autonomia: a liberdade de dispor, de contratar, de testar e de casar-se (TEPEDINO, 2006, p. 342).

Como não existe construção neutra ou norma jurídica que não envolva uma escolha, por trás dessa abstração havia a proteção de um único tipo de sujeito: aquele que, de fato, tinha condições materiais efetivas de exercer e se beneficiar dessa autonomia. O contratante, $\mathrm{O}$ marido, o bom pai de família, o testador, o proprietário, ou seja, o homem 
burguês era quem tinha poder para fazer uso das prerrogativas que o Direito de então assegurava (MORAES, 2010, p. 21).

A mulher, a criança, o adolescente, o idoso, o portador de necessidades especiais, o enfermo, enfim, todos aqueles que, por razões econômicas, sociais ou culturais, não conseguiam efetivamente se beneficiar dessa liberdade puramente formal permaneciam ocultos e oprimidos sob o manto da isonomia. Não se trata propriamente de novos sujeitos, mas de sujeitos cuja condição pessoal era indiferente para o Direito e, por isso, eram afligidos por certa "invisibilidade jurídica" (DALSENTER, 2007, p. 193).

Todos eles, por um fator da realidade concreta, sofrem dificuldade para exercer essa autonomia abstrata, de cunho estritamente patrimonial, que era dada na época a todos, indistintamente. Pela inexperiência, pela doença, pelo medo, seja por qual motivo for, todos esses vulneráveis têm algo que os preme e, por isso, garantir-Ihes a autonomia clássica, de molde patrimonial, é insuficiente.

Agora, o reconhecimento de sua vulnerabilidade impõe um tratamento normativo diferenciado, que busca empoderá-los na relação com os demais, de maneira a assegurar uma autonomia mais efetiva. Nesse sentido, são ditos novos sujeitos de direito, ou sujeitos merecedores de um tratamento jurídico diferenciado.

Embora o termo "vulnerabilidade" se tenha generalizado e seja usado para inferioridades puramente econômicas - como a consideração de que todo consumidor, até pessoas jurídicass, são vulneráveis -, por trás desses novos sujeitos há uma vulnerabilidade de natureza existencial, não patrimonial, pois a situação que limita sua autonomia os atinge diretamente na sua dignidade (KONDER, 2015, p. 114).

É importante, igualmente, não permitir que a vulnerabilidade sirva de estigma reducionista e aprisionador, como ocorreu com o conceito clássico de incapacidade. Em especial tratando-se de crianças e adolescentes pacientes, cuja condição que os vulnerabiliza pode ser temporária, é ainda mais importante evitar isso. O receio disso leva alguns autores, no caso de crianças e adolescentes, a preferir enfatizar 
a característica "em desenvolvimento" como sinal distintivo (SÊCO, 2014 , p. 15). No entanto, esse tipo de opção metodológica não resolve o risco para outros que se encontram em condição de vulnerabilidade, razão pela qual se entende que, em vez de rejeitar a categoria da vulnerabilidade, prioritário é abordá-la com cuidado, a fim que não sirva de pretexto para limitar as possibilidades de livre desenvolvimento de sua personalidade.

Nesse sentido, deve-se reconhecer que a categorização desses novos sujeitos, embora possa ser útil como forma de chamar atenção para as situações, não deve ser tida como uma enumeração taxativa. 0 fundamental é reconhecer que a vulnerabilidade existencial prescinde de qualquer tipificação,pois é decorrência da aplicação direta dos princípios constitucionais da dignidade da pessoa humana e da solidariedade social, devendo sempre ser avaliada em atenção às circunstâncias do caso concreto (KONDER, 2014, p. 93).

Isso fica claro quando abordamos hipóteses em que as vulnerabilidades se somam, acentuando-se mutuamente, como é o caso da criança paciente, objeto deste artigo. A condição de criança já coloca uma vulnerabilidade, decorrente da imaturidade, e a de paciente coloca outra, decorrente da fragilidade da integridade física do enfermo. Se cada uma delas já impõe um tratamento normativo diferenciado, em conjunto elas destacam situações cuja aplicação do princípio da dignidade da pessoa humana somente pode ser viabilizada em atenção às peculiaridades do caso concreto.

\section{0 paciente como sujeito ativo da relação com seu médico ${ }^{1}$}

A relação médico-paciente era vista por meio do tradicional modelo hipocrático paternalista e opressor, em que o médico tudo sabia e era soberano de todas as decisões a serem tomadas, pois detinha o

Algumas dessas ideias foram desenvolvidas no nosso TEIXEIRA, Ana Carolina Brochado.

Saúde, corpo e autonomia privada. Rio de Janeiro: Renovar, 2010. 
conhecimento e, a priori, sempre sabia o que era melhor para o paciente: "o médico é o pai e o doente é um incapaz; é um enfermo, um infirmus, um ente sem firmeza de julgamento e de vontade. O paciente não decidia nada; obedecia ao médico, com a convicção de que este procuraria, segundo o seu critério técnico, o seu bem" (OLIVEIRA, 2005, p. 110). Preponderava o princípio da beneficência, o qual pressupõe ações que não apenas não prejudiquem o paciente, mas também contribuam para o seu bem-estar, embora a partir do referencial do médico.

Essa lógica foi se transformando à medida que os direitos do paciente de participar do seu tratamento e definir o que fazer com seu corpo passaram a ser importantes, o que aconteceu conforme a integridade física passou a fazer parte dos direitos da personalidade, isto é, aspectos existenciais da pessoa humana passaram a receber proteção jurídica.

A discussão sobre a existência de direitos do paciente é consequência da centralidade da pessoa humana no sistema jurídico, derivada da tutela da sua dignidade e do livre desenvolvimento da sua personalidade. Essa mudança de posição da pessoa deu-lhe a possibilidade de se construir livremente, razão pela qual não poderia ficar alheia a interferências ou manipulações no seu corpo sem sua permissão ou contra a sua vontade em nome da proteção à sua integridade física. Trata-se da liberdade de decidir o que melhor lhe convém sobre o seu corpo, de autodeterminar-se em escolhas que envolvam a pessoa também na sua dimensão física. É a possibilidade de edificar a própria vida privada, a identidade pessoal, com ações que incidem sobre a esfera física. Por isso, o consentimento passou a ser entendido como um exercício da liberdade pessoal.

A partir daí, a relação entre médico e paciente teve que se modificar. De soberano das decisões, o médico passou a um papel mais informativo, aconselhador, interlocutor, dialógico com o enfermo (STANCIOLI, 2004, p. 27), transferindo para este a decisão sobre os rumos do seu tratamento, pois é ele o mais interessado em definir o destino a ser dado à sua saúde, à sua doença e ao seu tratamento. Não 
há mais uma relação de superioridade do médico sobre o paciente, mas de igualdade e cooperação entre eles.

Nesse novo contexto, é coerente abandonar a ideia de infantilização do paciente, que tem como pano de fundo um genuíno "paternalismo clínico", 2 que o trata como incapaz de decidir e participar do seu processo terapêutico, poupando-lhe de informações ruins sobre seu estado de saúde ou sobre a evolução da doença. O caminho para maior humanização desse relacionamento é o diálogo do médico com o paciente, conferindo-lhe informações para que ele possa decidir com responsabilidade. Na verdade, a manutenção do paternalismo significa a continuidade de uma relação autoritária, pois retira do enfermo a possibilidade de ele decidir sobre si mesmo, sobre suas condições de vida e sobre a maneira que pretende viver ante o diagnóstico.

Essa transformação só foi possível em razão da garantia do exercício de liberdades, o que inclui o direito de governar a própria vida, com o pleno exercício de soberania sobre seu corpo. "A revolução do consentimento informado modifica as hierarquias sociais recebidas, dando voz a quem era silencioso diante do poder do terapeuta e define uma nova categoria geral constitutiva da pessoa. Consentir equivale a ser" (RODOTÀ, 2009, p. 85). A pessoa assume a condição de sujeito e não mais de "objeto" de tratamento cujos rumos sempre foram decididos apenas pelo médico, fazendo nascer outros aspectos da sua subjetividade.

Pelo fato de não mais haver paternalismo quando há discernimento, informar ao paciente sobre a doença, o tratamento e os riscos que cada decisão envolve em linguagem compreensível é fundamental para que ele possa compreender sua situação e tomar decisões. De acordo com Tepedino (2006), cabe ao médico "o dever de fornecer ampla informação quanto ao diagnóstico e ao prognóstico", além do "emprego de todas as técnicas disponíveis para a recuperação do paciente, aprovados pela

Esta expressão é de Guilherme de Oliveira (2005, p. 61). 
comunidade científica e legalmente permitidas", uma vez que o foco é "a tutela do melhor interesse do enfermo em favor de sua dignidade e integridade física e psíquica” (TEPEDINO, 2006, p. 90). É esse conjunto de ações do médico que diminui a distância, a desigualdade da relação médico-paciente, de modo a aproximá-los, mesmo que seja pela linguagem. Isso se faz necessário para evitar uma relação arbitrária do médico sobre a integridade física do paciente. É por esse mecanismo que a pessoa passa a atuar e decidir. É necessário que o paciente esteja em condições de dar o seu consentimento livre e esclarecido ou consentimento informado -, que tem duplo caráter: i) reproduz um acordo de vontades entre médico e paciente após o adimplemento do dever de informar; ii) é condição de legitimidade da ação do médico, considerado terceiro, já que o ponto de referência é gozo de direitos de personalidade pelo paciente.

O consentimento para o tratamento ou não deve ser interpretado como expressão da subjetividade do próprio paciente, em nome da tutela da pessoa humana - e, é direito fundamental do paciente. Suas decisões autônomas deverão ser preservadas na maior medida possível, quando houver condições para o exercício de sua liberdade existencial. E as condições para que a autonomia sobre a integridade física seja exercida são: existir integridade psíquica e haver condições de expressar o seu consentimento.

Quando, contudo, não existirem esses pressupostos, a manifestação de vontade do sujeito estará contaminada pelos efeitos da doença; sua liberdade estará prejudicada exatamente pela condição que o torna vulnerável. Nesse caso, limitar-se a levar em conta o que o sujeito diz querer, ou mesmo impor-lhe o peso de tomar a decisão sozinho, significa, na prática, desconsiderar sua vulnerabilidade e, portanto, subjugar sua dignidade. Quando a pessoa estiver em uma situação de vulnerabilidade que a prive da integridade psíquica ou das condições de expressar livremente seu convencimento, o que deve prevalecer é o melhor interesse do paciente, por meio da utilização de técnicas eficientes para o alívio da dor. A autonomia, nesse caso, deve 
ceder lugar à aplicação do princípio da solidariedade. ${ }^{4}$ É o caso, muitas vezes, da situação da criança e do adolescente.

\section{A tutela jurídica da menoridade ${ }^{5}$}

Com o advento da Constituição Federal de 1988, criança e adolescente ganharam proteção especial por serem pessoas em processo de desenvolvimento. O ordenamento jurídico deles cuidou de forma acurada, por estarem em fase de construção da sua personalidade e dignidade. Foi um "investimento" normativo que se fez na infância e na juventude, chancelado pelas diretrizes principiológicas contidas no bojo do Estatuto da Criança e do Adolescente, Lei nº 8.069/90.

Essa mudança entrelaçou-se com a fase de transição do perfil da família, a qual vem delineando, com o passar do tempo, novos contornos, cujos reflexos inevitáveis repercutiram nas relações parentais. O conteúdo das relações parentais sofreu efetivas transformações: de uma perspectiva formal e autoritária do pátrio poder, passou-se a um vínculo dialógico e ativo da autoridade parental, no qual ganha relevo o processo educacional, cuja função é tornar os filhos pessoas autônomas e responsáveis.

Isso se justifica pelo comando constitucional que determina que seja dado à população infantojuvenil um tratamento prioritário, como pessoas em desenvolvimento e alvo da proteção integral da família, da sociedade e do Estado, cujo melhor interesse deve ser preservado a qualquer custo. São alvos de especial tratamento das entidades intermediárias, passando a ser os protagonistas da família.

4 Em nome do pluralismo e da autonomia - que possibilita que cada um escolha o estilo de vida que melhor o realize -, caso o paciente tenha deixado Diretivas Antecipadas de Vontade, que sejam respeitadas em nome do exercício de sua autonomia, expressa validamente quando tinha condições para tal.

5 Algumas dessas reflexões foram trabalhadas no nosso TEIXEIRA, Ana Carolina Brochado. Familia, guarda e autoridade parental. 2. Ed. Rio de Janeiro: Renovar, 2009. 
O princípio do melhor interesse da criança e do adolescente ${ }^{6}$ obteve tamanha prioridade no âmbito do Direito de Família, quando o debate cingiu-se aos direitos do menor, que - ao lado e funcionalizado ao Princípio da Dignidade Humana - passou a ser o vértice interpretativo do ordenamento nessa seara. Para garantir sua aplicação em toda e qualquer relação intersubjetiva que tenha como parte(s) criança e/ou adolescente, escora-se, também, na Doutrina da Proteção Integral e da Parentalidade Responsável, diretrizes normativas e hermenêuticas a direcionar o intérprete diante da situação concreta.

Como poderíamos definir o Princípio do Melhor Interesse da Criança? Segundo Tânia da Silva Pereira (1999, p. 3), "a aplicação do princípio do best interest permanece como um padrão considerando, sobretudo, as necessidades da criança em detrimento dos interesses de seus pais, devendo realizar-se sempre uma análise do caso concreto". Como todo princípio, não há como definir aprioristicamente seu conteúdo, devendo-se buscar em cada caso a forma de concretizá-lo.

Afirma Maria Clara Sottomayor (2002, p. 197) que, embora o interesse da criança ou do adolescente seja um conceito indeterminável, pelo seu caráter vago e elástico, facilitando interpretações subjetivas, tem um núcleo conceitual que deve ser preenchido por valorações objetivas. Estas se atrelam à estabilidade das condições de vida da criança, das suas relações afetivas e do seu ambiente físico e social.

Poderíamos dizer que o núcleo conceitual nomeado pela autora portuguesa encontra-se exatamente na possibilidade de acesso e exercício dos direitos fundamentais pela criança e pelo adolescente. Tal princípio, aliado à doutrina da proteção integral, visa à proteção da criança, do adolescente, bem como de seus direitos, além de garantir-lhes

6 O Princípio do Best Interest foi consagrado no $7^{\circ}$ Princípio da Declaração dos Direitos da Criança, de 1959, e prevê que "os melhores interesses da criança serão a diretriz a nortear os responsáveis pela sua educação e orientação; esta responsabilidade cabe, em primeiro lugar, aos pais". A Convenção Internacional sobre os Direitos da Criança, de 1989 , declarou, no art. $3^{\circ}, 1$, que "Todas as ações relativas às crianças, levadas a efeito por instituições públicas ou privadas de bem-estar social, tribunais, autoridades administrativas ou órgãos legislativos, devem considerar primordialmente, o melhor interesse da criança". 
as mesmas prerrogativas que cabem aos adultos. O dever de proteção não se limita ao Estado, mas também é atribuído à sociedade e à família, conforme determina o art. 227 da Carta Constitucional. Sua condição prioritária deve-se ao fato de serem pessoas em desenvolvimento cuja personalidade deve ser protegida e promovida, mediante o exercício dos direitos fundamentais. ${ }^{6}$

Despiciendo, neste momento, questionarmos qual a forma de acesso e exercício dos direitos fundamentais pela população infantojuvenil, ao que nos parece, a relação parental é o modo prioritário, em regra, de assegurar-lhes a experiência de tais direitos, tendo em vista que o relacionamento familiar é a primeira experiência do menor com o outro, principalmente com os pais. É a experiência primeira da alteridade. Esse "outro", por sua vez, recebeu do Estado um múnus, um feixe de poderes e deveres a serem exercidos em benefício dos filhos, o que nos autoriza a caracterizar a autoridade parental como poder jurídico, no que tange às inúmeras categorias das situações jurídicas subjetivas.

Diante do conteúdo constitucional da autoridade parental, que impõe aos pais os deveres de criar, assistir e educar os filhos menores, a função do instituto é instrumentalizar os direitos fundamentais dos filhos, tornando-os pessoas capazes de exercer suas escolhas pessoais, com a correlata responsabilidade.

Ante as diretrizes constitucionais e estatutárias que ressaltam a função promocional do Direito, o relacionamento entre genitores e filho passou a ter como objetivo maior tutelar a personalidade deste e, portanto, o exercício de seus direitos fundamentais, para que possa, nesse contexto, edificar sua dignidade enquanto sujeito. A autoridade parental, nesse aspecto, foge da perspectiva de poder e de dever para exercer sua sublime função de instrumento facilitador da construção da

6 Tal condição Ihes foi garantida pelo art. $6^{\circ}$ da Lei 8.069/90, Estatuto da Criança e do Adolescente, cujo teor é o seguinte: "Art. $6^{\circ} \mathrm{Na}$ interpretação desta Lei levar-se-ão em conta os fins sociais a que ela se dirige, as exigências do bem comum, os direitos e deveres individuais e coletivos, e a condição peculiar da criança e do adolescente como pessoas em desenvolvimento." 
autonomia responsável dos filhos. Nisso consiste o ato de educá-los, decorrente dos Princípios da Parentalidade Responsável e da Doutrina da Proteção Integral, ambos com sede constitucional, ao alicerce de serem pessoas em fase de desenvolvimento, o que lhes garante prioridade absoluta.

Os filhos, como foi mencionado, não são sujeitos passivos da relação com os pais. ${ }^{7}$ Também não constituem objeto dos poderes e deveres embutidos no conteúdo da autoridade parental. Tornaram-se protagonistas da própria história e do próprio processo educacional. A função educativa se consubstancia em um processo dialético entre pais e filhos, o que é consequência do seu direito fundamental à liberdade, também previsto pelos arts. 15 e 16 do Estatuto da Criança e do Adolescente (ECA).

Os menores devem ser respeitados em seus valores e crenças,merecem respeito por serem pessoas e, principalmente, por estarem em processo de desenvolvimento. Seu papel ativo cresce conforme adquirem discernimento e sua liberdade é acompanhada pela correlata responsabilidade. Por isso, o ECA prevê direitos fundamentais, como a participação nas decisões mais relevantes da própria vida, tais como ser ouvido no processo de adoção, ${ }^{8}$ nos atos e medida de promoção e proteção dos seus direitos, ${ }^{9}$ nas ações de suspensão ou

7 De acordo com a habitual sabedoria de Luiz Edson Fachin, "os filhos não são (nem poderiam ser) objeto da autoridade parental. Em verdade, constituem um dos sujeitos da relação derivada da autoridade parental, mas não sujeitos passivos (...)" (Elementos críticos do direito de família. In: LIRA, Ricardo Pereira (Coord.). Curso de direito civil. Rio de Janeiro: Renovar, 1999, p. 223.

8 Art. 28, § 2o ECA. Tratando-se de maior de 12 (doze) anos de idade, será necessário seu consentimento, colhido em audiência. A oitiva dos menores se faz relevante, também, no Direito Penal, conforme Súmula 265 STJ: "É necessária a oitiva do menor infrator antes de decretar-se a regressão da medida sócio-educativa".

9 Art. 100 ECA. Na aplicação das medidas levar-se-ão em conta as necessidades pedagógicas, preferindo-se aquelas que visem ao fortalecimento dos vínculos familiares e comunitários. Parágrafo único. São também princípios que regem a aplicação das medidas: (...)XII - oitiva obrigatória e participação: a criança e o adolescente, em separado ou na companhia dos pais, de responsável ou de pessoa por si indicada, bem como os seus pais ou responsável, têm direito a ser ouvidos e a participar nos atos e na definição da medida de promoção dos direitos e de proteção, sendo sua opinião devidamente considerada pela autoridade judiciária competente, observado o disposto nos $\S \S 10$ e 20 do art. 28 desta Lei. 
perda do poder familiar. ${ }^{10}$ A jurisprudência, no entanto, tem estendido a possibilidade de oitiva em outras situações, como algumas hipóteses de repatriação ${ }^{11}$ e guarda. ${ }^{12}$

É louvável a atribuição de validade à vontade da criança e do adolescente para a prática de atos existenciais, principalmente em razão da dificuldade funcional de se separar titularidade de exercício de direitos da personalidade. Todavia, deve-se levar em consideração o estágio de desenvolvimento e maturidade em que o menor se encontra,

10 Art. 161, § 3o Se o pedido importar em modificação de guarda, será obrigatória, desde que possível e razoável, a oitiva da criança ou adolescente, respeitado seu estágio de desenvolvimento e grau de compreensão sobre as implicações da medida.

11 DIREITOINTERNACIONAL. CONVENÇÃODAHAIASOBREASPECTOS CIVISDOSEQUESTRO INTERNACIONAL DE CRIANÇAS. COOPERAÇÃO JURÍDICA ENTRE ESTADOS. BUSCA, APREENSÃO E RESTITUIÇÃO DE MENORES. GUARDA COMPARTILHADA. OCORRÊNCIA DE RETENÇÃO ILÍCITA DOS FILHOS POR UM DOS GENITORES. PAÍS DE RESIDÊNCIA HABITUAL. JUIZZO NATURAL COMPETENTE PARA DECIDIR SOBRE A GUARDA. PRESENÇA DE HIPÓTESE EXCEPCIONAL. CESSAÇÃO DOS EFEITOS DA CONVENÇÃO PARA OS MAIORES DE 16 ANOS. IRMÃ COM 17 ANOS E IRMÃO COM 15 ANOS E MEIO. CESSADOS OS EFEITOS DA CONVENÇÃO EM RELAÇÃO À IRMÃ. REPATRIAMENTO ISOLADO APENAS DO IRMÃO MAIS JOVEM. PROVIDÊNCIA MERECEDORA DE BOM SENSO E PRUDÊNCIA. OITIVA DO ADOLESCENTE QUANTO AO DESEJO DE RETORNO AO PAÍS DE RESIDÊNCIA HABITUAL. NECESSIDADE. (...)

6. A Convenção sobre os Aspectos Civis do Sequestro Internacional de Crianças não mais opera seus efeitos quando a criança completa dezesseis anos, nos termos do art. $4^{\circ}$ do referido documento.

7. No caso, a Convenção cessou seus efeitos em face da jovem de 17 anos; porém, ainda opera seus efeitos no tocante ao jovem de 15 anos. Hipótese em que se adota o entendimento segundo o qual repatriar a apenas o irmão, enquanto a irmã permanecerá no Brasil, soa prejudicial ao melhor interesse daquele, pois, não bastasse a alienação reprovável promovida pela sequestradora, o menor seria submetido também ao distanciamento geográfico da irmã. Em observância ao bom senso e à prudência, a oitiva do jovem de 15 anos sobre eventual desejo de retornar ao país de residência habitual e a avaliação pericial de suas condições psicológicas são medidas que se impõem." (Resp 1196954/ES, T2, Min. Humberto Martins, 25/2/2014, Dje 13/3/2014)

12 AGRAVO DE INSTRUMENTO - MÃE QUE JÁ DETÉM A GUARDA - AUSÊNCIA DE RISCO IMINENTE AO MENOR - NECESSIDADE DE DILAÇÃO PROBATÓRIA - MANUTENÇÃO DO "STATUS QUO" - RECURSO NÃO PROVIDO.

1. Na definição da guarda, ainda que em caráter liminar, o julgador deve levar em consideração os princípios do melhor interesse da criança, da parentalidade responsável e da proteção integral, observando as peculiaridades do caso concreto, sendo de extrema importância a manifestação da vontade do menor, quando possível. 2. Não demonstrada a premente necessidade de transferir o adolescente à guarda paterna, deve ser mantida a situação fática delineada até que os fatos sejam esclarecidos com a oitiva do menor em juízo e ampla instrução probatória. (TJMG, Al nº, $5^{\mathrm{a}} \mathrm{CC}, \mathrm{Rel}^{\mathrm{a}}$. Des ${ }^{\mathrm{a}}$. Aurea Brasil, J. 22/5/2014, DJe 30/5/2014). 
a fim de se verificar qualitativamente os tipos de atos que ele pode expressar, de forma a implementar o seu melhor interesse. A autonomia a ser protegida, portanto, é a autonomia responsável, que mede e suporta as consequências dos seus atos. Por isso, a tutela da criança e do adolescente que protege e promove seus melhores interesses existenciais deve ser balizada pela investigação do seu discernimento, do estágio de completude do seu desenvolvimento cognitivo. Pois, na falta de condições para tal, são os pais quem deverão fazê-lo, tendo em vista que a tutela da menoridade pressupõe a identificação do estágio em que se encontra o progressivo processo de maturação. Isso não significa alijar o menor de participar da situação, respeitando O conteúdo e a extensão do que ele compreende.

Participar não significa, necessariamente, decidir. Remete a ter informações sobre a situação que lhe acomete, em linguagem compreensível para a sua idade. Significa não ser considerada como objeto. ${ }^{13} \mathrm{O}$ relevante para este estudo é que a criança ou o adolescente faça parte desse processo, sendo sujeito ativo com as naturais limitações impostas pela idade. No entanto, isso não significa impor-lhe o encargo de sempre decidir sozinho, ou a responsabilidade pela decisão a ser tomada, especialmente quando isso for incompatível com o seu grau de discernimento e maturidade. É com a sua participação, assim como com a participação dos pais/responsáveis e equipe médica, dialogicamente, que serão buscadas a definição e a concretização do seu melhor interesse para as decisões referentes à sua saúde.

\section{Desafios da tutela do paciente menor de idade}

Pensar sobre os direitos do paciente menor de idade é um grande desafio, pois coloca em evidência o choque entre três atores

\footnotetext{
13 A fala de uma criança de 13 anos ilustra o que estamos a afirmar: "Às vezes eu não pergunto, porque eu me irrito. Eu perguntei o que era isso aqui [mostra a pele no braço], o que eu tinha, falaram que era de coçar... mas eu tenho desde de pequena, como vai ser de eu coçar? $\mathrm{E}$ a mulher [médica] fez assim, nem olhou em mim, e falou que era de eu coçar. [...] Eu pergunto, mas não adianta. Eles [médicos] não resolvem. Eu já perguntei para ela [médica] um dia, daí agora eu parei de perguntar (Simone, 13 anos)." (GABARRA; CREPALDI, 2011, p. 213).
} 
que participam desse processo. Primeiro, a criança/adolescente, cuja autonomia é paulatinamente adquirida no âmbito do seu processo educacional, na medida em que alcança maior compreensão do mundo à sua volta, bem como o direito de participar das decisões referentes ao seu tratamento de saúde.

Se um prejuízo à condição de saúde fragiliza a autonomia de qualquer ser humano, a criança e o adolescente certamente não são exceções. Consciente, ao menos em alguma medida, do que acontece ao seu redor, destaca-se a importância de incluir o paciente no processo decisório, incutindo na criança um vínculo de confiança nos médicos e nos próprios pais, e viabilizar que ela se expresse, especialmente quanto às suas fantasias e medos: "apesar dessa realidade, é preciso entender que falar da morte pode aliviar e ajudar a criança a elaborar suas perdas" (TOMA; OLIVEIRA; KANETA, 2014).

Nessas questões envolvendo paciente menor de idade, existe um vácuo legislativo no que diz respeito à análise processual da aquisição de discernimento da criança e do adolescente, em face da sua realidade ser extremamente dinâmica. No entanto, além da aplicação do ECA, destaca-se a Resolução n 41/1995 do Conselho Nacional dos Direitos da Criança e do Adolescente (CONANDA), elaboradae apresentada pela Sociedade Brasileira de Pediatria, que versa sobre os direitos da criança e do adolescente hospitalizados (TOMA; OLIVEIRA; KANETA, 2014).

O segundo ator envolvido nesse processo são os pais, que naturalmente se encontram fragilizados e pressionados pela ameaça à saúde de seu filho. O papel dos pais no tratamento dos filhos menores é reconhecido hoje entre os profissionais atuantes na esfera hospitalar, devendo ser integrado no processo terapêutico, até mesmo para aumentar a eficácia do tratamento. Informados adequadamente e atendidos com solicitude pelos profissionais de saúde, os pais são determinantes na desconstrução - ou na construção - de um ambiente de estresse e insegurança para o paciente (MELO; FERREIRA; LIMA; MELLO, 2014). 
É fundamental que os pais sejam assistidos adequadamente pela equipe hospitalar, de forma cuidadosa e não paternalista, pois já se encontram premidos pelo estresse e pela responsabilidade de tomar decisões referentes à saúde e vida de seu filho. O próprio ambiente hospitalar, com suas regras e rotinas, intimida e limita os familiares e, no mais das vezes, as condutas dos membros da equipe hospitalar prejudicam seu envolvimento no processo terapêutico, pois "não contemplam as necessidades da família de solidariedade, aproximação, empatia, estabelecimento de vínculos, responsabilizações e acolhimento que contribuiriam para que essa se sinta segura e fortalecida diante do processo de hospitalização de sua criança" (XAVIER; GOMES; SANTOS; LUNARDI; PINTANEL; ERDMANN, 2014).

O terceiro ator envolvido nesse processo é a equipe médica, cujo conhecimento científico deve servir de guia para o melhor encaminhamento da situação, mas jamais como decisão final, pois deve assumir uma postura dialógica, reconhecendo a autonomia dos envolvidos, em especial a do paciente. De fato, é importante ter em mente que, embora caiba ao médico assistir os pais, seu dever prima facie é perante o paciente, cuja identidade, individualidade e autonomia devem ser reconhecidas. Por isso, a oitiva da criança e do adolescente é fundamental.

No silêncio do legislador, no mais das vezes, acaba ficando a critério do médico ouvir ou não seu paciente, razão pela qual sobejam relatos em que o paciente menor é desconsiderado como partícipe dessa relação: "A avaliação das condições pessoais do menor, assim como o maior ou menor respeito à sua vontade, inclusive no que respeita ao sigilo, em face da vontade dos representantes legais, estão a cargo exclusivo do médico" (BARBOZA, 2004, p. 45).

O atual Código de Ética Médica (Resolução do CFM n 1931/2009), em seu art. 74, veda "ao médico revelar sigilo profissional a paciente menor de idade, inclusive a seus pais e representantes legais, desde que o menor tenha capacidade de discernimento, salvo quando a não revelação possa acarretar dano ao paciente". O reconhecimento da 
privacidade do paciente menor de idade coincide com o conceito a este direito de personalidade pensado por Stefano Rodotà (2008, p. 17), que é o controle sobre as próprias informações. Mas observe-se que o próprio Código de Ética Médica ressalva que uma das exceções ao exercício da privacidade, nesse caso, é o risco de o sigilo médico gerar danos ao paciente, o que justificaria a revelação da situação aos pais e representantes legais. ${ }^{14}$

Trabalhos doutrinários na área médica identificam uma mudança no comportamento do médico quando o paciente é criança e quando é adolescente: na primeira hipótese, a relação é entre médico e responsável legal; mas no segundo caso, passa a ser entre médico e adolescente, razão pela qual é necessário que este seja ouvido a sós pelo médico (TAQUETTE; VILHENA; SILVA; VALE, 2005). Mas mesmo quando se tratar de criança, esta deve ser informada e pode expressar sua opinião, pois ela tem o direito de participar da sua construção biográfica. No caso do adolescente, ele já pode decidir, sobre seu desenvolvimento cognitivo e moral:

A possibilidade de entregar a responsabilidade ao adolescente sobre seus direitos de personalidade não o sobrecarrega, pois ele agirá sobre os direitos de personalidade, na medida de sua evolução cognitiva e moral, podendo recorrer aos pais e responsáveis, se ainda não se sentir capaz de tomar a decisão ou se o médico em sua avaliação entender que ele não está preparado para tomar a decisão. A criança por sua vez, quando ainda muito pequena não participará de decisões efetivamente

14 Percebem-se dificuldades relativas à confidencialidade da relação médico-paciente menor, especialmente quanto aos adolescentes em início da vida sexual. Pesquisa feita no ambulatório e enfermaria do Núcleo de Estudos da Saúde do Adolescente, Universidade Estadual do Rio de Janeiro (NESA/UERJ) sobre a saúde do adolescente detectou que as principais causas que reclamavam a necessidade de revelação do sigilo médico a terceiros " $\mathrm{C}$ - e que não contavam com a anuência do adolescente quanto à quebra da confidencialidade - se referiam a "atividade sexual de risco, gravidez, doenças sexualmente transmissíveis, AIDS, aborto, uso de drogas, depressão e suicídio. Exemplos: adolescentes grávidas que se negam a comunicar esse fato aos responsáveis e avisam que vão abortar; adolescentes HIV+ que não aceitam revelar seu diagnóstico à família." (TAQUETTE, VILHENA, SILVA, VALE, 2005). 
importantes, mas poderá realizar pequenas escolhas. $\mathrm{Na}$ idade escolar, no entanto a criança já poderá participar por meio do assentimento ou dissentimento de tratamentos e procedimentos. A criança que já possui capacidade de participar da decisão tampouco ficará sobrecarregada, porque ela não é parte efetiva da decisão final, sendo essa responsabilidade destinada aos pais ou responsáveis. (MUNHOZ, 2014, p. 146).

A oitiva é relevante, pois existem dados que o paciente não deseja revelar perto de seus pais, devendo o médico mostrar-se como pessoa merecedora da confiança do menor, sendo também oportunidade importante para que o médico possa conhecer melhor as condições cognitivas do seu paciente, a fim de poder balizar o peso da expressão da sua vontade.

É claro que, para que o menor possa opinar e sua manifestação de vontade ser levada em consideração, é de grande relevância que as suas condições pessoais sejam consideradas, pois é importante verificar sua real competência, ou seja, o seu grau de entendimento sobre a doença que lhe acomete e o impacto em sua vida. Embora seja possível se pensar em condições gerais para cada faixa etária, é importante que a própria criança seja avaliada em seu contexto de vida, pois o nível de desenvolvimento pode ser diferente entre as crianças. ${ }^{15}$ Nesse sentido, explica Heloísa Helena Barboza (2004, p.44):

Parece razoável a orientação no sentido de que, sempre que possível, se cumpra a regra do Estatuto, ou seja, se ouça a criança ou adolescente, respeitando sua vontade,

15 "[...] características do desenvolvimento devem ser levadas em consideração: Trata-se de um processo que evolui continuamente à medida que habilidades se aperfeiçoam, novas capacidades são adquiridas, novas vivências são acumuladas e integradas e, portanto, passível de rápidas e extremas mudanças no tempo; 1. A aquisição das competências é progressiva, não se dá saltos, como se se tratasse de compartimentos estanques, e segue sempre uma ordem preestabelecida, sendo, portanto, razoavelmente previsível; 2 . Os tempos e o ritmo em que o desenvolvimento se processa são muito individualizados, fazendo com que dois indivíduos de uma mesma idade possam estar em momentos diferentes de desenvolvimento; 3 . No caso específico da inteligência, o desenvolvimento é extremamente influenciável por fatores extrínsecos ao indivíduo: as experiências, os estímulos, o ambiente, a educação, a cultura, etc., o que também acaba por reforçar sua evolução extremamente individualizada". (LEONE, 1998). 
desde que não agrave seu estado ou ponha sua vida em perigo. Em outras palavras, consideradas as condições pessoais do paciente menor, sua idade, capacidade de percepção e de cumprir as prescrições médicas, deve-se respeitar, o quanto possível e razoável, o consentimento livre e esclarecido da criança e do adolescente.

Dois casos de menores ingleses colocaram essa discussão em pauta: Hanna Jones e Reece Puddington. A primeira foi uma jovem inglesa que desde os cinco anos de idade se tratava em virtude de leucemia mieloide aguda. Os fortes medicamentos atacaram o coração, exigindo o implante de marca-passo e transplante cardíaco. Após avaliar os riscos e as chances de sucesso da cirurgia, quando Hanna tinha treze anos, manifestou seu desejo de interromper o tratamento hospitalar e ir para casa residir com os pais. O hospital entrou na Justiça para que a adolescente se tratasse compulsoriamente, mas após passar por entrevistas com uma assistente social, esta atestou que Hanna estava segura da sua decisão de não ser operada e recebeu apoio de seus pais. $^{16}$

Reece Puddington, que aos cinco anos descobriu ser portador de neuroblastoma, decidiu aos 11 anos interromper o tratamento. Continuar o tratamento significa lidar com viagens ao hospital, efeitos colaterais, novos exames etc. Foi por isso que a criança comunicou aos seus seguidores do Facebook que deixaria a natureza seguir seu curso. ${ }^{17}$

Para que pacientes menores de idade possam se manifestar, principalmente em situações irreversíveis, é muito importante que se forme um elo de confiança entre paciente-, médico e -pais, pois existem inúmeras situações em quenas quais o adolescente não terá condições de se expressar validamente. Além disso, é fundamental que se levelevar em conta o grau de maturidade e as suas condições pessoais

16 Disponível em: < http://goo.gl/zelXMY >. Acesso em: 15 nov. 15.

17 "Minha mãe sempre esperou, nos últimos 5-6 anos, o momento em que precisaria ter coragem para entender que 'basta' significasse 'basta'. Após cuidadosa consideração, ela percebeu que, se fosse por ela, continuaria a me levar para o tratamento e não me deixaria ir, mas se fosse por mim, ela me deixaria partir. Bem, ela está me deixando ir". Disponível em: <http://goo.gl/406y4Kl>. Acesso em: 15 nov. 2015. 
na consideração de sua vontade. Nesse sentido, afirma Luciana Batista Munhoz:

A opinião da criança deve versar sobre uma série de questões atinentes ao seu tratamento, como por exemplo, se ela está disposta a receber o tratamento naquele momento, qual o braço que ela dará para a enfermeira, estimulando-a sempre fazer escolhas. É importante reconhecer que o desenvolvimento da capacidade se dá individualmente e que nem sempre as crianças irão conseguir atuar no nível ótimo sua autonomia, dessa forma não se pode exigir requisitos para o exercício da autonomia superiores aos demandados para os adultos.

Percebe-se, portanto, a relevância da participação dos três atores dessa relação. Não é possível prever, de antemão, a intensidade dessa participação quando se trata de paciente menor de idade, pois será necessário verificar a sua capacidade de compreensão da sua realidade e das consequências das decisões a serem tomadas de forma individualizada. O papel dos pais ou responsáveis é complementar, pois eles devem agir, sempre, quando não há possibilidade do exercício de autonomia, completando a vontade do filho, esclarecendo, apoiando, advertindo... A decisão dos pais só deverá prevalecer quando o paciente não tiver nenhuma condição de opinar "C- mesmo assim, apenas se a definição dos pais se coadunar com a ideia de respeito aos melhores interesses do paciente menor de idade. ${ }^{18} \mathrm{O}$ médico, terceiro interlocutor do processo, funciona como coadjuvante de grande relevância, pois suas informações funcionarão como gatilho de todo o processo decisório a respeito do tratamento ou não tratamento. O respeito do papel de

18 Vale citar uma situação em que os pais, por proefessarem uma religião que vedam a transfusão de sangue, decidem que o filho não poderá se submeter a esse tratamento. Tratava-se de um menor portadora de leucemia, internadoa em uma UTI pediátrica de um hospital de uma cooperativa de saúde em Vitória/-ES, responsável pelo ajuizamento de ação contra os pais. A transfusão era a única forma de manter a criança, não sendo possível dizer que a própria criançaela, se tivesse discernimento, faria essa escolha, razão pela qual a conduta é pela manutenção da vida. (Notícia disponível em http://www.gazetaonline.com.br/_conteudo/2015/09/noticias/cidades/3909558justica-autoriza-medicos-a-realizarem-transfusao-em-crianca-com-leucemia.html. Acesso em 2.12.2015) 
cada um é fundamental, para que autonomia e solidariedade sejam complementares - e não opositoras - no difícil processo de maturação do paciente menor de idade.

\section{Conclusão}

O panorama aqui traçado, embora não permita inferir decisões definitivas, revela a necessidade de levar em conta algumas premissas ao tratar de crianças e adolescentes que se encontrem na condição de pacientes. Inicialmente, deve-se ter em mente a vulnerabilidade decorrente de sua condição de pessoa humana, cuja identidade e discernimento ainda se encontram em desenvolvimento. Essa vulnerabilidade faz com que a garantia pura e simples de autonomia formal, em abstrato, acabea por desproteger esse sujeito mais do que tutelá-lo.

Por outro lado, observou-se que tanto na relação entre o menor e seus pais, como na relação entre pacientes e médicos houve uma transformação no equilíbrio de forças, passando de um paternalismo forte para o reconhecimento da importância do diálogo e de tutela dos interesses e desejos da parte vulnerável. Isso implicou o direito de voz e decisão dos menores na medida do seu discernimento e maturidade, e a garantia de autonomia do paciente no que diz respeito à sua saúde e ao seu tratamento médico.

No âmbito específico da complexa relação entre o menor paciente, os pais e a equipe médica, observou-se a necessidade de um procedimento dialógico e inclusivo, que permita a todos os agentes envolvidos se expressarem e que demandae, por parte da equipe médica, cuidado e atenção; , por parte dos pais, responsabilidade e ponderação; e, por parte do menor, o direito de ser ouvido e de suas manifestações serem levadas em conta na medida de seu discernimento. 


\section{Referências}

ASCENSÃO, José de Oliveira. Introdução à ciência do direito. 3. ed. Rio de Janeiro: Renovar, 2005.

BARBOZA, Heloísa Helena. Poder familiar em face das práticas médicas. Revista do advogado, São Paulo, v. 76, n. 76, jun. 2004, p. 40-46.

. Vulnerabilidade e cuidado: aspectos jurídicos. In: PEREIRA, T. S.; OLIVEIRA, G. (Coord.). Cuidado e vulnerabilidade. São Paulo: Atlas, 2009. p. 106-118.

BOBBIO, Norberto. Dalla strutura alla funzione: nuovi studi di teoria del diritto. Milano: Edizioni di Comunità, 1977.

DALSENTER, Thamis Ávila. Transexualidade: a (in) visibilidade imposta pelo judiciário. Revista Trimestral de Direito Civil, Rio de Janeiro, v. 31, p. 193-206, 2007.

FACHIN, Luiz Edson. Teoria crítica do direito civil. Rio de Janeiro: Renovar, 2000.

GABARRA, Letícia Macedo; CREPALDI, Maria Aparecida. A comunicação médico-paciente pediátrico: família na perspectiva da criança. Psicol. Argum., Curitiba, v. 29, n. 65, p. 209-218, abr./jun. 2011.

KONDER, Carlos Nelson de Paula; DALSENTER, Thamis. Questões atuais da responsabilidade civil médica e hospitalar. In: Ana Carolina Brochado Teixeira; Luciana Dadalto. (Org.). Dos hospitais aos tribunais. Belo Horizonte: Del Rey, 2013. p. 463-498.

KONDER, Carlos Nelson. Vulnerabilidade patrimonial e vulnerabilidade existencial: por um sistema diferenciador. Revista de Direito do Consumidor, v. 99, p. 101-123, 2015.

. Vulnerabilidade, hipervulnerabilidade ou simplesmente dignidade da pessoa humana? Uma abordagem a partir do exemplo do consumidor superendividado. In: MONTEIRO FILHO, C. E. R. (Coord.). Direito das relações patrimoniais: estrutura e função na contemporaneidade. Curitiba: Juruá, 2014. p. 69-93. 
LEONE, Claudio. A criança, o adolescente e a autonomia. Revista bioética, Brasília, v. 6, n. 1, 1998.Disponível em:

<http://revistabioetica.cfm.org.br/index.php/revista_bioetica/article/ view/324/392>. Acesso em: 12 dez. 2015

MELO, Elsa Maria de Oliveira Pinheiro de; FERREIRA, Pedro Lopes; LIMA, Regina Aparecida Garcia de; MELLO, Débora Falleiros de.

The involvement of parents in the healthcare provided to hospitalzed children. Revista Latino-Americana de Enfermagem, Ribeirão Preto, v. 22, n. 3, mai./jun. 2014.

MCGUIRE, Amy L. Keeping childrens' secreet: confidentiality in the physician patient relationship. Houston Journal of Health Law \& Policy, Houston, v. 8, n. 2, p. 325-333, 2007-2008.

MORAES, Maria Celina Bodin de. Na medida da pessoa humana. Rio de Janeiro: Renovar, 2010.

MUNHOZ, Luciana Batista. O princípio da autonomia progressiva e a criança como paciente. 2014. 160 f. Dissertação (Mestrado em Bioética) - UNB, Brasília, 2014. Disponível em: <http://repositorio.unb. br/bitstream/10482/15918/1/2014_LucianaBatistaMunhoz.pdf>. Acesso em:? 20 nov. 2015

OLIVEIRA, Guilherme. O fim da "arte silenciosa". In: OLIVEIRA, Guilherme. Temas de direito da medicina. Coimbra: Coimbra Editora, 2005. p. 105-114.

PEREIRA, Tânia da Silva. O "melhor interesse da criança". In: PEREIRA, Tânia da Silva (Coord.). O melhor interesse da criança: um debate interdisciplinar. Rio de Janeiro: Renovar, 1999. p. 1-101.

RODOTÀ, Stefano. Perché laico. Roma-Bari: Laterza, 2009.

RODOTÀ, Stefano. A vida na sociedade da vigilância. Rio de Janeiro: Renovar, 2008.

SÊCO, Thaís Fernanda Tenório. Por uma nova hermenêutica do direito da criança e do adolescente. Civilistica.com, Rio de Janeiro, ano 3, n. 2, p. 1-26, 2014. 
SOTTOMAYOR, Maria Clara. Quem são os verdadeiros pais? Adopção plena de menor e oposição dos pais biológicos. Direito e Justiça:

Revista da Faculdade de Direito da Universidade Católica Portuguesa, Lisboa, v. XVI, t. I, p. 191-241, 2002.

STANCIOLI, Brunello Souza. Relação jurídica médico-paciente. Belo Horizonte: Del Rey, 2004.

TAQUETTE, Stella; VILHENA, Marília Melo de; SILVA, Mariana Maurício; VALE, Mônica Pereira. Conflitos éticos no Atendimento à saúde de adolescentes. Cad. Saúde Pública, Rio de Janeiro, v.21, n.6, p. 1717-1725, nov./dez. 2005.

TEIXEIRA, Ana Carolina Brochado. Família, guarda e autoridade parental. 2. ed. Rio de Janeiro: Renovar, 2009.

. Saúde, corpo e autonomía privada. Rio de Janeiro:

Renovar, 2010.

TEPEDINO, Gustavo. A responsabilidade médica na experiência brasileira contemporânea. In: . Temas de direito civil. Rio de Janeiro: Renovar, 2006. p. 83-121. t. II.

. Do sujeito de direito à pessoa humana. In: Temas de direito civil. Rio de Janeiro: Renovar, 2006. p. 340-342. t. II.

TOMA, Marjory Dionizio; OLIVEIRA, Walter Lisboa; KANETA, Catalina Naomi. Comunicação de prognóstico reservado ao paciente infantil. Revista Bioética, Brasília, v. 22, n. 3, set./dez. 2014.

XAVIER, Daiani Modernel et al. A família na Unidade de Pediatria: convivendo com normas e rotinas hospitalares. Revista brasileira de enfermagem, Brasília, v. 67, n. 2, mar./abr. 2014. Disponível em: <http://www.scielo.br/scielo.php?script=sci_arttext\&pid=S0034$71672014000200181 \&$ Ing=pt\&nrm=iso\&tlng=pt>. Acesso em: $09 \mathrm{dez}$. 2015

Recebido em: 18/01/2016

Aprovado em: 07/03/2016 